\title{
Estrogen receptor alpha deficiency protects against development of cognitive impairment in murine lupus
}

Melissa A Cunningham*, Jena R Wirth, Linnea R Freeman, Heather A Boger, Ann-Charlotte Granholm and Gary S Gilkeson

\begin{abstract}
Background: One of the more profound features of systemic lupus erythematosus (SLE) is that females have a 9:1 prevalence of this disease over males. Up to 80\% of SLE patients have cognitive defects or affective disorders. The mechanism of CNS injury responsible for cognitive impairment is unknown. We previously showed that ERa deficiency significantly reduced renal disease and increased survival in lupus-prone mice. We hypothesized that ERa deficiency would be similarly protective in the brain, and that ERa may play a role in modulating blood-brain barrier (BBB) integrity and/or neuroinflammation in lupus-prone mice.

Methods: MRL/lpr ERa+/+ and ERaKO mice $(n=46)$ were ovariectomized, received $17 \beta$-estradiol pellets, and underwent radial arm water maze (WRAM) and novel object recognition (NOR) testing starting at eight weeks of age. Mice were sacrificed and brains were hemisected and processed for either immunohistochemistry, or hippocampus and parietal cortex dissection for Western blotting.

Results: MRL/Ipr ERaKO mice $(n=21)$ performed significantly better in WRAM testing than wild-type MRL/lpr mice $(n=25)$. There was a significant reduction in reference memory errors $(P<0.007)$, working memory errors $(P<0.05)$, and start arm errors $(P<0.02)$ in ERaKO mice. There were significant differences in NOR testing, particularly total exploration time, with ERa deficiency normalizing behavior. No significant differences were seen in markers of tight junction, astrogliosis, or microgliosis in the hippocampus or cortex by Western blot, however, there was a significant reduction in numbers of Iba1+ activated microglia in the hippocampus of ERaKO mice, as evidenced by immunohistochemietry (IHC).
\end{abstract}

Conclusion: ERa deficiency provides significant protection against cognitive deficits in MRL/lpr mice as early as eight weeks of age. Additionally, the significant reduction in Iba1+ activated microglia in the MRL/lpr ERaKO mice was consistent with reduced inflammation, and may represent a biological mechanism for the cognitive improvement observed.

Keywords: Estrogen receptor alpha (ERa), Neuropsychiatric lupus (NP-SLE), Microglia

\footnotetext{
*Correspondence: cunnima@musc.edu

Division of Rheumatology and Immunology, Department of Neurosciences, and Ralph $\mathrm{H}$ Johnson Veterans Affairs Hospital, Medical University of South Carolina, 96 Jonathan Lucas Street, Suite 814, MSC637, Charleston, SC 29425, USA
} 


\section{Background}

Systemic lupus erythematosus (SLE) is the prototypic autoimmune disease characterized by production of autoantibodies and immune complex-mediated end-organ damage. Nine out of ten patients diagnosed with lupus are female, thus biologic sex is important in disease development [1]. The cause of the sex difference in SLE is likely multifactorial, including the sex chromosomes, sex hormones, and their receptors. A high incidence of neuropsychiatric involvement is being increasingly recognized. Symptoms of neuropsychiatric SLE (NP-SLE) are variable [2], however, certain symptoms are more common than others, with up to $80 \%$ demonstrating cognitive defects and/or affective disorders $[3,4]$. Neuroimaging of these patients, even those without clinical symptoms, reveals structural changes such as non-focal atrophy. On the other hand, cognitive behavioral deficits in lupus can be observed in the absence of gross central nervous system (CNS) pathology, and do not correlate well with serologic or disease activity measures [3,5]. Additionally, up to 40\% of NP-SLE symptoms develop before or at the time of SLE diagnosis, and approximately $60 \%$ manifest within the first year $[6,7]$. Taken together, these data suggest a primary CNS-specific mechanism that is largely independent of disease flare or cumulative damage. The mechanism(s) of CNS injury responsible for the cognitive and psychological impairments in SLE are currently unclear.

Autoantibodies cross-reacting with N-Methyl-D-aspartate (NMDA) receptors in the brain mediate excitotoxic cell death, causing impairments in cognition and other behavioral changes in lupus-prone mice [8-10]. Similar disease manifestations are present in humans who have elevated cerebrospinal fluid (CSF) titers of these autoantibodies [11-13]. Biochemical studies in the affected mice revealed neuronal cell loss by apoptosis in targeted areas such as the hippocampus and lateral amygdala $[8,14,15]$. A breach in the blood-brain barrier (BBB) is required for these effects. Thus, BBB breakdown, pathogenic autoantibodies, and subsequent neuronal damage in key areas may be involved in the development of NP-SLE.

There is robust evidence that hormonal changes alter BBB integrity, which may predispose to different outcomes following pathological insult. Estrogen acts primarily via its receptors, ER $\alpha$ and $E R \beta$, nuclear transcription factors involved in the regulation of many complex physiological processes. Thus, estrogen receptor modulators are being considered for a wide variety of conditions in humans [16]. Numerous studies have shown protective effects of estrogen in acute neurologic insult models (such as stroke, traumatic brain injury, and experimental autoimmune encephalomyelitis) [17-20]. In SLE and several other chronic inflammatory diseases, however, data suggest the opposite; estrogen has pro-inflammatory effects, such as enhancing humoral immunity, while progesterone and androgens are immunosuppressive [21-25]. Elevated estrogen levels may lead to prolonged or dysfunctional inflammatory responses. Our lab previously derived lupus-prone ER $\alpha$ deficient $(E R \alpha K O)$ mice, and found that female MRL/lpr ER $\alpha K O$ and NZM2410 ER $\alpha$ KO mice developed significantly less proteinuria and pathologic renal disease, and had significantly prolonged survival [21]. We subsequently showed that innate immune cells (dendritic cells) from $\mathrm{ER} \alpha \mathrm{KO}$ mice have a blunted inflammatory response (for example, reduced levels of IL-6, MCP-1, and IL- $1 \beta$ to Toll-like receptor (TLR) ligands, partially explaining the protected phenotype [26].

Microglia are the innate immune cells of the CNS and respond to both external and internal stimuli with a cascade of reactive cytokines that can act in either a pro- or anti-inflammatory fashion [27]. Microglia originate from bone marrow-derived monocytes and migrate to the CNS, accounting for approximately 5 to $10 \%$ of CNS cells. Under normal conditions, microglia are actively surveying their environment, and after pathologic insult they become activated, undergoing dramatic changes in morphology and function, with concomitant increases in expression of CD11b and Iba1. Both ER $\alpha$ and ER $\beta$ are expressed in microglia, however ER $\alpha$, but not ER $\beta$, is required for activation, consistent with what is observed in peripheral innate immune cells $[28,29]$.

Since female lupus-prone ER $\alpha$ KO mice are protected from renal disease, we investigated the effects of ER $\alpha$ deficiency on CNS disease. Given the known cognitive dysfunction in both human and murine lupus, we evaluated cognitive endpoints, specifically spatial and visual memory, following early ovariectomy and estradiol repletion to normalize estrogen levels in female lupus-prone wildtype (WT) and ER $\alpha \mathrm{KO}$ animals. We subsequently examined the brains of these animals, with specific attention to the microglia, given the importance of ER $\alpha$ in innate immune cells. In this study, we show for the first time that the cognitive impairment seen in lupus-prone MRL/lpr mice is significantly improved in ER $\alpha$-deficient littermates. Importantly, ER $\alpha$-deficient mice have significantly fewer activated microglia in the CA1 and dentate regions of the hippocampus, despite no significant differences in autoantibody levels or systemic hormone levels, suggesting that ER $\alpha$ plays a critical role in the activation and/or development of immune cells involved in lupus CNS disease.

\section{Methods}

Mice

Mice were maintained at the Ralph $\mathrm{H}$ Johnson VA Medical Center Animal Facility (Charleston, South Carolina, United States). Animal protocols followed the principles outlined in the Guide for the Care and Use of Laboratory Animals, and were approved by MUSC's IACUC (Institutional 
Animal Care and Use Committee), protocol \#559. ER $\alpha$ KO mice of the C57BL/6 strain (kind gift of Dr Ken Korach) were backcrossed to MRL/lpr mice (Jackson Laboratory, Bar Harbor, Maine, United States) as previously described [21]. All experimental mice $(n=46)$ were female, either $\mathrm{ER} \alpha+/+$ or ER $\alpha \mathrm{KO}$, using littermates when possible. Mice were ovariectomized (OVX) using isoflurane (Patterson Veterinary, Devens, Massachusetts, United States) and held for two weeks to recover and eliminate endogenous ovarian steroids. At six weeks of age, a $0.25 \mathrm{mg} 90$-day time-release $17 \beta$-estradiol pellet (Innovative Research, Sarasota, Florida, United States, catalog number NE-121) was implanted sub-dermally in the dorsal neck. A $0.25 \mathrm{mg}$ pellet results in serum levels averaging between 70 and $300 \mathrm{pg} / \mathrm{ml}$.

\section{Radial arm maze apparatus and testing procedure}

The radial arm water maze (WRAM) task is used to measure spatial (working and reference) memory [30-32]. For details of WRAM testing, please see Additional file 1. Briefly, animals were introduced to WRAM testing at eight weeks of age (two weeks after E2 pellet implantation). The eight-arm water maze was constructed of galvanized steel and filled with room-temperature water. See Hyde et al. for detailed information on procedure and a comparative analysis of three mouse strains (BXSB, NZB, and C57BL/6) [33]. The maze was located in a room with salient extramaze cues on three walls, and the same experimenter in a yellow gown in the fourth position (start arm). For every trial, a subject was allowed 120 seconds to swim through the maze and locate a platform. Each subject received one session (four trials) per day for 12 days. A swim test, including velocity testing and sight testing, was conducted on day zero to ensure that animals were physically capable of performing in the maze. Data are presented as the average errors per session or per learning phase, similar to the methods described in Bimonte and Denenberg, and Alamed et al. [32,34].

\section{Novel object recognition}

Recognition memory tasks utilize animal tendency to spend more time exploring novel objects compared to familiar objects. This task is known to involve both frontal cortex and hippocampal function [35]. For full details of novel object recognition (NOR) testing procedure, see Additional file 1. Briefly, on days one and two, the animal was habituated to the learning environment to reduce anxiety. On day three the animal was exposed to a threeminute familiarization session (identical objects present, $\mathrm{A} / \mathrm{A})$. The animal then performed a three-minute testing session after a 90-minute delay (A/B). On day four, the animal was tested with a second new object $(\mathrm{A} / \mathrm{C})$. The time to first contact, total amount of time spent with each object, as well as number of contacts were recorded and scored. The $\mathrm{D}^{2}$ index was calculated for an $\mathrm{A} / \mathrm{B}$ or $\mathrm{A} / \mathrm{C}$ session by examining the difference in time spent exploring the novel and familiar objects divided by the total exploration time for both objects:

$$
\mathrm{D}^{2}=\left(\mathrm{T}_{\mathrm{n}}-\mathrm{T}_{\mathrm{f}}\right) / \text { Total time. }
$$

\section{Serum anti-dsDNA and serum estradiol}

Serum was collected from WT and ER $\alpha$ KO female MRL/lpr mice at sacrifice. Serum anti-dsDNA was measured by ELISA assays as previously described [36]. Estradiol levels were assessed via ELISA (Calbiotech, San Diego, California, United States) [37]. The OVX + E2 mice averaged 379 pg/ml circulating estradiol. The sensitivity of the assay was $3 \mathrm{pg} / \mathrm{ml}$; precision: 3.1\% (intra-assay), 9.9\% (inter-assay) [38].

\section{Western blotting}

At the time of sacrifice, brains were quickly removed and hemisected. One hemisphere was post-fixed for immunohistochemistry. The other hemisphere was dissected to harvest hippocampus, pre-frontal cortex, nucleus accumbens, and a piece of parietal cortex, all of which were snap frozen and stored at $-80^{\circ} \mathrm{C}$. Tissue was sonicated in a modified RIPA (150 mM NaCL, 50 mM Tris-HCl, pH 7.4, and $0.1 \%$ sodium dodecyl sulfate) buffer with protease (Thermo Scientific, Rockford, Illinois, United States) and phosphatase inhibitors (Sigma, Saint Louis, Missouri, USA). Lysates were analyzed by $10 \%$ SDS-PAGE and transferred to a polyvinylidene fluoride membrane (Life Technologies - Invitrogen, Grand Island, New York, United States). After blocking, the membrane was incubated with rabbit anti-tight junction protein Zo-1 (Invitrogen, number: 61-7300), anti-occludin (Invitrogen, number: 40-4700), anti-Iba1 (Wako, Richmond, Virginia, United States, number: 019-19741), anti-Microtubule Associated Protein 2 (MAP2) (Abcam, Cambridge, Massachusetts, United States, number: 32454), or mouse anti- Glial fibrillary acidic protein (GFAP) (Cell Signaling, Danvers, Massachusetts, United States, number: 3670).

\section{Immunofluorescence}

For immunohistochemical analysis, one hemisphere was post-fixed in $4 \%$ paraformaldehyde for 48 hours, and then transferred to $30 \%$ sucrose (Thermo Fisher Scientific, Waltham, Massachusetts, United States, number: S5500) in $0.1 \mathrm{M}$ phosphate buffered saline (PBS) and $0.1 \%$ sodium azide (Thermo Fisher Scientific, number: S2271-500) before sectioning. The hemisphere was sectioned on a cryostat (Microm, Zeiss, Dublin, California, United States) at $40 \mu \mathrm{m}$ and processed for immunohistochemical analyses as described previously [39]. Briefly, series of every sixth section were blocked in 10\% normal goat serum (NGS, Invitrogen, number: 10000C) in Tris Buffered 
Saline (Thermo Fisher Scientific, number: BP152-5)Triton X-100 (Thermo Fisher Scientific, number: BP151$100)$ and incubated with anti-Iba1 (Abcam, number: 153696), Alexa-fluor 488 conjugated rabbit polyclonal anti-Neu1 (Millipore, Billerica, Massachusetts, United States, number: ABN78A4), or Alexa-fluor 488 conjugated mouse monoclonal antibody against MAP2 (Millipore, number: MAB3418X) overnight at room temperature. The sections were then incubated for one hour with secondary antibodies directed against the appropriate species, conjugated with tetramethylrhodamine (TRITC, 1:200) (Jackson Immunoresearch, West Grove, Pennsylvania, United States). The tissue was mounted onto slides, and cover-slipped with an anti-fade solution (Fisher Scientific, Fair Lawn, New Jersey, United States). All images we captured using a Nikon Eclipse E-600 microscope equipped with a Qcam digital camera (Nikon Instruments Inc., Melville, New York, United States).

\section{Iba1 cell counts}

The density of Iba1 immunoreactive microglial cells in the hippocampus was investigated because of this brain region's proven role in both of the behavioral tasks employed herein. Our group has previously demonstrated significant alterations in microglial activation in the CA1 and dentate regions of the hippocampus in other chronic inflammatory conditions, such as following long-term exposure to a high-fat diet [40]. A series of every sixth section throughout the rostrocaudal extent of the hippocampus was evaluated. Images were acquired on a Nikon microscope, and settings remained identical across all data acquisition. Using the NIS-Elements Advanced Research software system from Nikon (Nikon Instruments Inc.), the region of interest (ROI) was outlined and the number of Ibal immunoreactive cells was counted by an investigator blinded to the group identity. The number of Iba1 immunoreactive cells was expressed as the average number of cells observed within one field of vision using a $10 \times$ objective, averaged across three randomly selected visual fields within each tissue section. The results were averaged per animal and data analyzed using an unpaired Student's $t$-test (Graphpad, La Jolla, California, United States) between the two groups.

\section{Statistical analysis}

For WRAM studies, repeated measures ANOVA was utilized for learning curves, and a Mann-Whitney nonparametric $t$-test was utilized to test for significance between the two mouse groups. For NOR studies, one-way ANOVAs were performed followed by post-hoc analysis with Tukey's multiple comparison testing. Iba1 immunoreactive cell counts were analyzed using an unpaired Student's $t$-test. Standard error of the means (SEM) was reported where applicable. $P$ values $\leq 0.05$ were considered significant. All statistical analyses were performed using GraphPad Prism Version 5.0 Software.

\section{Results}

Hormone and autoantibody levels

MRL/lpr ER $\alpha$ WT and ER $\alpha$ KO female mice were OVX at three to four weeks of age and an estrogen pellet was placed at six weeks of age. Estradiol pellets (extended release) were designed to approximate physiologic levels of estradiol (approximately $100 \mathrm{ng} / \mathrm{ml} /$ day). Given that estrogen improves performance by rodents in the WRAM [41], we confirmed that there were no significant differences in serum estradiol levels between the MRL/lpr and MRL/lpr ER $\alpha$ KO mice (Figure 1A). There was also no correlation between estradiol levels in individual mice and performance in the WRAM, as measured by late (days 10 to 12) reference memory errors (Figure 1B).

Overall lupus disease burden of MRL/lpr and MRL/lpr ER $\alpha$ KO mice was previously characterized by our laboratory [21]. Despite significant differences in renal disease, non-manipulated ER $\alpha K O$ female animals did not have diminished serum autoantibody levels. In this study, using OVX MRL/lpr mice (WT and ER $\alpha \mathrm{KO}$ ), anti-dsDNA levels were again not significantly different (Figure 1C). These results suggest that variance in autoantibody and hormone levels by themselves do not explain the behavior differences noted in these two groups of mice.

\section{Radial arm water maze testing}

The WRAM task utilized here tests spatial reference and working memory [42], while the NOR task has been associated with both hippocampal and frontal cortex function [35]. During the habituation trial on day one, swim tests were performed by all animals $(48 \mathrm{~cm}$ to unconcealed center platform with large flag). Animals took approximately two seconds to reach the center platform after release and no impairments in swimming speed or ability to utilize visual cues were observed in either MRL/lpr or MRL/lpr ER $\alpha$ KO mice $(1.76 \pm 0.35$ versus $2.19 \pm 0.94$ seconds, respectively).

Four orthogonal measures of reference and working memory were obtained for each daily session: working memory correct errors, reference memory errors, working memory incorrect errors, and start arm errors. Reference memory errors were the number of first entries into an arm that had never contained a platform. Additional file 2: Table $\mathrm{S} 1$ lists the $\mathrm{N}$ (number of animals), means +/SE (standard error) for the number of errors made. The one-within (session) repeated measures ANOVA $\left(F \mathrm{~s}_{1,11}=\right.$ 4.09; $P<0.01)$ revealed a main effect of sessions while a $t$-test (genotype) for days 1 to 12 did not reveal a significant effect of genotype, most likely due to the increased errors seen in MRL/lpr ER $\alpha K O$ mice mid-training. Figure 2A shows the learning curve. As expected, there 


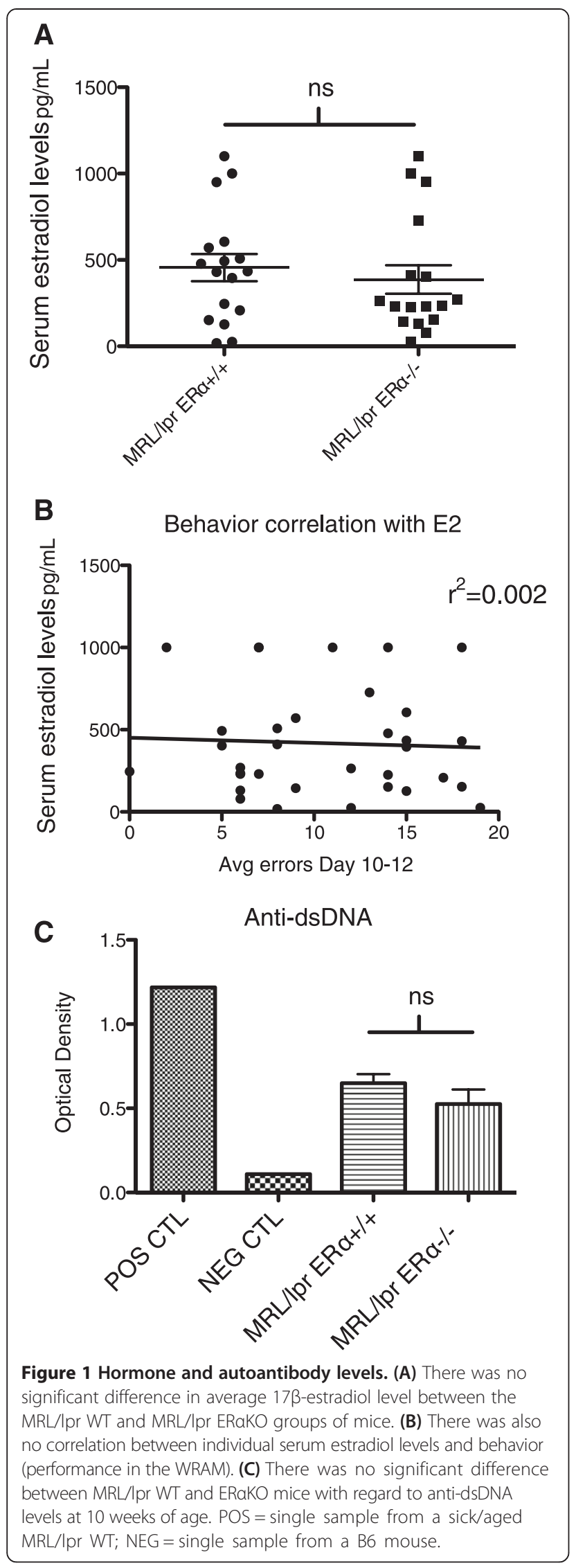

was no significant difference between the two groups early in training (the acquisition phase), however, by the end of training (the asymptotic phase), MRL/lpr ER $\alpha$ KO mice clearly outperformed MRL/lpr mice, with significantly fewer errors made in the late or asymptotic phase (days 10 to $12 ; P<0.007$ ) (Figure $2 \mathrm{~B}$ ).

Working memory incorrect (WMI) errors were the number of repeat entries into an arm that never contained a platform. Additional file 2: Table S2 lists the the $\mathrm{N}$, means $+/$ - SE for the number of errors made. There was no significant difference between the two groups early in training, but again by the end of training, MRL/ lpr ER $\alpha K O$ mice improved their average error rate, with significantly fewer errors made (days 10 to 12 ) versus MRL/lpr mice $(P<0.05)$ (Figure $2 \mathrm{C})$. Similar performance between the two groups in the acquisition phase suggests that there was no significant difference between the groups in terms of motivation to learn or perform the task, thus providing some information regarding mood and/or motivation. Working memory correct errors were scored as the number of first and repeat entries into an arm of the maze where a platform had been removed during the session. Additional file 2: Table S3 lists the N, means $+/$ - SE for the number of errors made by MRL/lpr versus MRL/lpr ER $\alpha$ KO mice. There was a significant difference between the two groups in average errors made in the late/asymptotic phase of training (days 10 to 12). MRL/lpr ER $\alpha$ KO made significantly fewer errors than MRL/lpr mice $(P<0.03)$ (Figure $2 \mathrm{D})$, suggesting that MRL/lpr ER $\alpha K O$ mice showed enhanced learning for the task. It should be noted, however, that the learning curves for both groups of mice suggest that neither group reduced the error rate to the extent expected for a normal mouse [32,43].

Lastly, start arm errors were recorded as any entry in arm five, which is the release arm. Since the examiner sits at the end of this arm, there is a strong visual cue. Animals must learn not to return to their release point, as it never holds a platform. Again, MRL/lpr ER $\alpha$ KO mice made significantly fewer errors (days 10 to 12 ) versus MRL/lpr mice $(P<0.02)$ (Figure 3$)$.

\section{Novel object recognition testing}

The NOR task is utilized to detect improvement (or disturbance) of non-spatial memory [44]. It requires a capacity for both identification and judgment of the prior occurrence of what has been identified. This visual recognition memory is evolutionarily conserved among species, and requires the hippocampus $[45,46]$.

Analysis of performance by standard NOR formulas (recognition index (RI) and relative discrimination index) revealed that there was no significant effect of genotype on the overall discrimination performance during 90-minute and 24-hour retention trials $(F(3,55)=1.125$, ns). Figure $4 \mathrm{~A}$ 

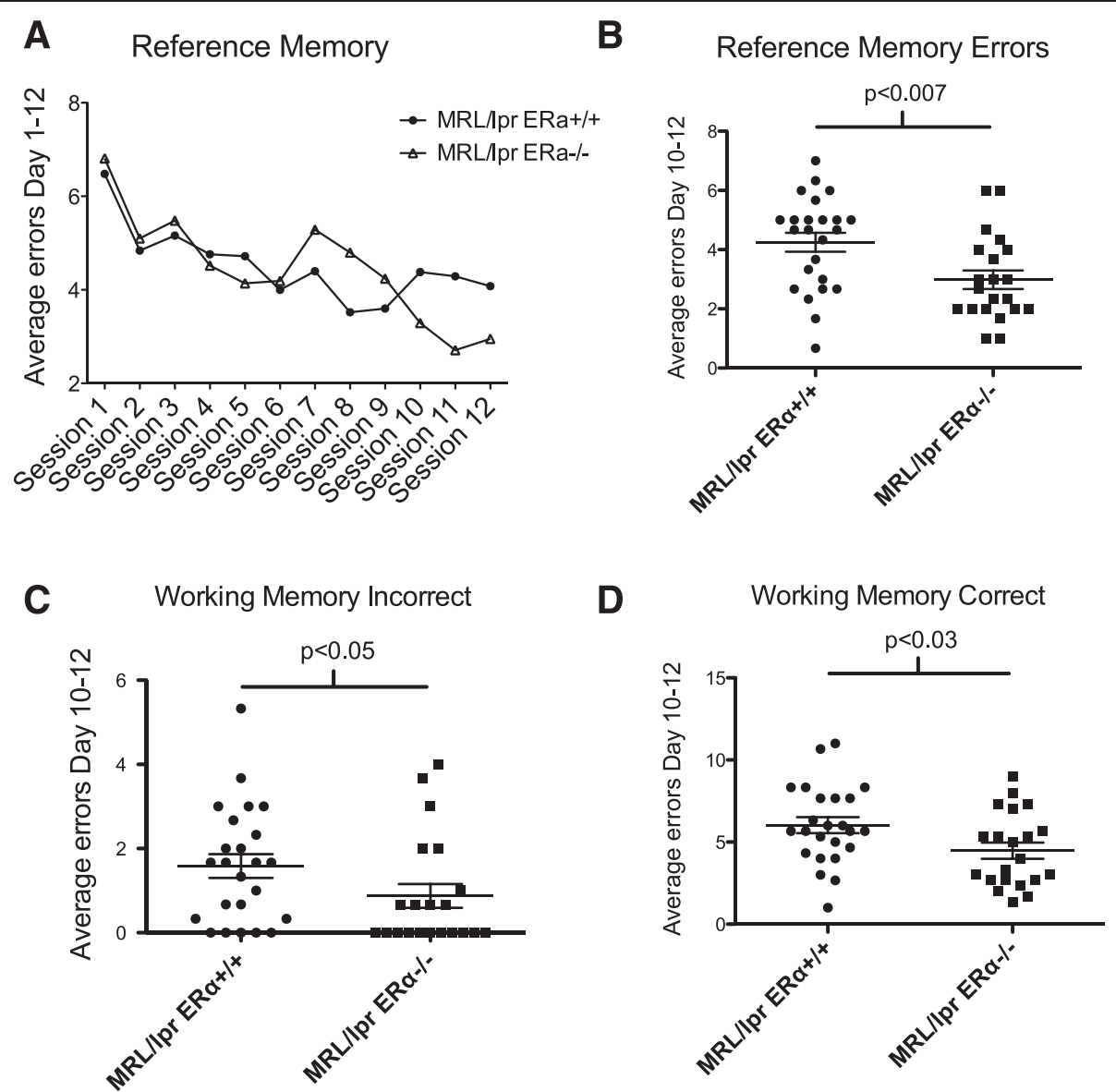

Figure 2 MRL/Ipr ERaKO mice perform better than MRL/Ipr WT in WRAM testing. (A) Reference memory learning curve. The one-within (session) repeated measures revealed a significant effect of sessions for days 1 to 12. (B) In the late or asymptotic phase (days 10 to 12), MRL/lpr ERaKO mice outperformed MRL/lpr mice, with significantly fewer reference memory errors made. (C, D) Average errors made in the late or asymptotic phase (days 10 to 12) revealed that MRL/pr ERaKO mice made significantly fewer errors than MRL/lpr mice in both working memory incorrect and working memory correct errors.

shows the relative discrimination $(\mathrm{N}-\mathrm{F} / \mathrm{T})$ index. A relative discrimination index of $0 \%$ (dotted line) indicates chance performance. There was a non-significant trend towards increased discrimination ability of the MRL/lpr versus MRL/lpr ER $\alpha K O$ at 24 hours $(P<0.07)$. Although there were individuals who could perform the task, neither group, as a whole, could effectively discriminate between the novel and familiar objects, suggesting abnormal behavior in both groups. This is in contrast to what was shown by other groups comparing $\mathrm{MRL} / \mathrm{lpr}$ to $\mathrm{MRL} /+$ mice $[47,48]$ in which MRL/lpr mice did not exhibit abnormal behavior in this task.

An unexpected result was the significant difference in total exploration times between MRL/lpr and ER $\alpha \mathrm{KO}$ mice in both the 90 minute and 24 hour trials (strain: $F$ $(3,57)=7.135 ; P<0.0004)$. Post-hoc analysis revealed that the total exploration time in both T1 and T2 of MRL/lpr ER $\alpha K O$ mice was significantly higher than that of MRL/lpr mice $(P<0.05)$ (Figure 4B).
When measuring latency (time to first contact) and contact ratio (number of contacts with novel/familiar), there was improved recognition of novel versus familiar object in the MRL/lpr ER $\alpha$ KO mice. At 90 minutes, the latency ratio (time to novel/time to familiar) was significantly decreased in the MRL/lpr ER $\alpha$ KO mice $(P<0.05)$ (Figure 4C). There was a trend towards improved behavior of MRL/lpr ER $\alpha K O$ at 24 hours. The percent of MRL/lpr ER $\alpha$ KO mice with a latency ratio less than one (novel preference) was $92 \%$ (12 out of 13 ) versus only $60 \%$ (9 out of 15) of MRL/lpr mice. Similarly, at 24 hours, $77 \%$ (10 out of 13) of MRL/lpr ER $\alpha K O$ had a latency ratio less than one versus only $50 \%$ ( 8 out of 16 ) of MRL/lpr mice. With regard to nose contacts, MRL/lpr ER $\alpha \mathrm{KO}$ mice made significantly more contacts with the novel object than the familiar object at 24 hours $(P=0.04)$, and at 90 minutes there was a trend towards significance $(P=0.07)$ (Figure 4D). In total, $43 \%$ (6 out of 14 ) of ER $\alpha \mathrm{KO}$ mice made more contacts with the novel versus familiar object, whereas 


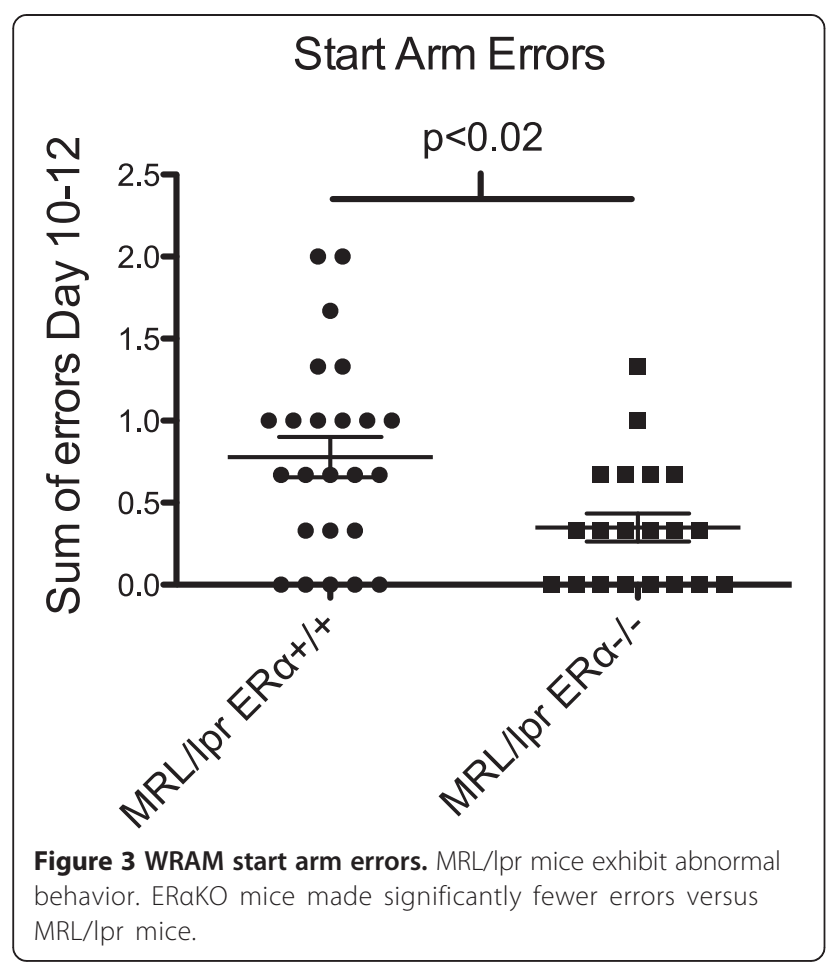

only $13 \%$ (2 out of 15 ) of the WT MRL/lpr did so after a 24-hour delay. These results suggest that there was improved recognition of novel versus familiar objects by MRL/lpr ER $\alpha$ KO mice. While the behavior is not normal in either group, ER $\alpha$ deficiency improved their performance in NOR testing.

\section{Global hippocampal expression of tight junction proteins Zo-1 and occludin}

Autoantibodies cross-reacting with NMDA receptors in the brain can mediate excitotoxic neuronal cell death, which causes impairments in cognition and other behavioral changes in lupus-prone mice [8-10]. A breach in the $\mathrm{BBB}$ is required for these effects. Estrogen, in multiple studies, protects the BBB in both normal aging and in certain disease states, and this effect is dependent on $\mathrm{ER} \alpha$ or $\beta[20,49,50]$.

To test whether BBB permeability may play a role in the cognitive differences seen in MRL/lpr versus MRL/lpr ER $\alpha$ KO animals, we measured several tight junction proteins that are surrogate markers of $\mathrm{BBB}$ integrity using Western blot analysis. We prepared whole cell lysates of the hippocampus from MRL/lpr and ER $\alpha$ KO mice $(n=9$ WT, 9 ER $\alpha K O$ ) and did Western blot analysis for Zo-1 or occludin. We did not see any global change in Zo-1 (Additional file 2: Figure S1A) or occludin (data not shown) at 10 weeks of age in the hippocampus or cortex of MRL/lpr versus ER $\alpha \mathrm{KO}$ mice, although there was a trend towards reduced Zo-1 in MRL/lpr ER $\alpha$ KO mice. These findings do not exclude potential morphological alterations at the microstructural level of BBB integrity in any of the groups as a result of the manipulation.

Global hippocampal expression of GFAP, Iba1, and MAP2 Neurologic disorders often lead to activation of resident microglia and invasion of blood-borne macrophages, which are accompanied by an increase in number and change in phenotype of astrocytes, a phenomenon generally termed reactive astrocytosis. We previously demonstrated that $\mathrm{ER} \alpha$ plays a role in modulating inflammation in lupusprone mice [26]. We hypothesized that a potential role for $E R \alpha$ in CNS disease is by modulating inflammatory mediators that lead to astrocytosis, microgliosis, and/or neuronal/dendritic loss. To test this hypothesis we prepared whole cell lysates of the hippocampus from MRL/ lpr and ER $\alpha$ KO mice $(\mathrm{n}=18)$ and did Western blot analysis for GFAP (an integral protein in astrocytes), Iba1 (marker of microgliosis), and MAP2 (marker of neuronal growth, plasticity, and degeneration). We did not see global changes in these markers at 10 weeks of age in the hippocampus (Additional file 2: Figure S2A,B,C) or cortex (data not shown). There was a trend towards decreased Iba1 in the cortex of MRL/lpr ER $\alpha$ KO mice, but it did not reach significance. Protein analysis of whole tissue homogenates may not always detect discrete differences observed in specific cell populations in the brain, making morphological assessment of both glial markers necessary.

\section{Central nervous system inflammatory changes}

Given our previous data, we hypothesized that ER $\alpha$ deficiency would decrease inflammation in the brain, leading to protection against neuronal loss (correlating with improved behavior). Utilizing immunohistochemistry to assess hippocampal structure, we noted that several animals had hippocampal (CA1 thinning) or cortical lesions, but these lesions did not correlate with ER $\alpha$ status or behavior. Overall, there were no significant differences seen in hippocampal structure utilizing NeuN immunostaining (a marker for neuronal cell bodies, Figure 5) or MAP2 immunostaining (a marker for dendritic integrity, Additional file 2: Figure S3), although multiple MRL/lpr animals had reduced overall MAP-2 signal in the hippocampus, suggesting reduced numbers of dendrites and dendritic complexity in MRL/lpr versus MRL/lpr ER $\alpha$ KO mice.

As described above, there were no global differences in microgliosis in the hippocampus or cortex seen by Western blot analysis. We subsequently examined localized changes by immunohistochemistry using the microglial marker Iba1. Again, gross hippocampal and cortical abnormalities were found in both groups. Almost all animals had some level of inflammation in both the hippocampus and the cortex, as evidenced by diffuse activated astrocytes or clustered microglia (Figure 6), however the level of microglial activation appeared to be significantly 
A

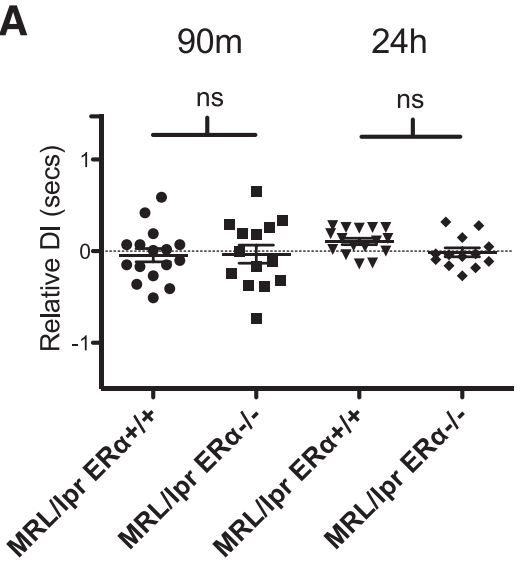

C

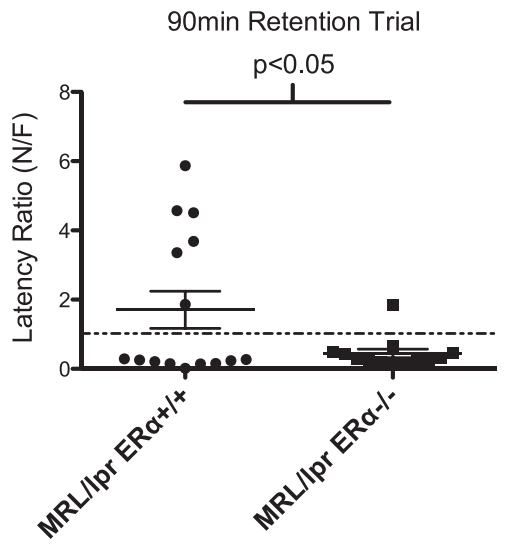

D

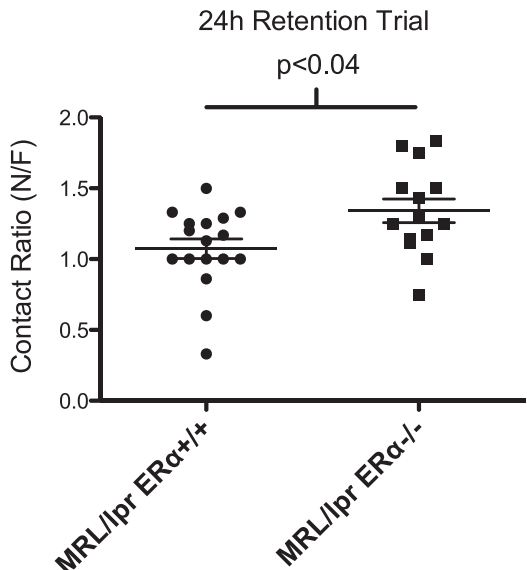

B

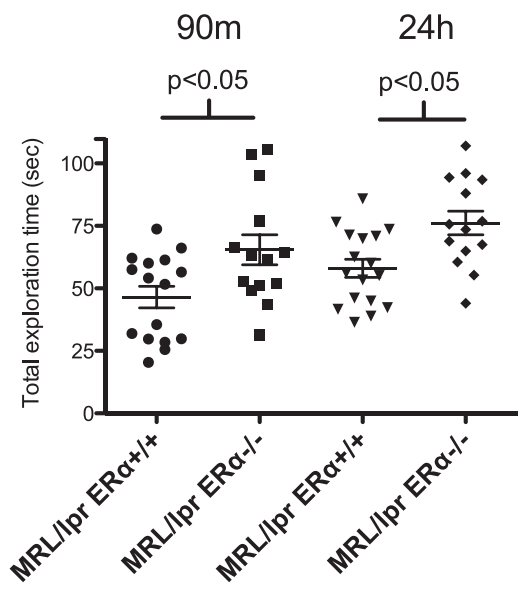

24h Retention Trial

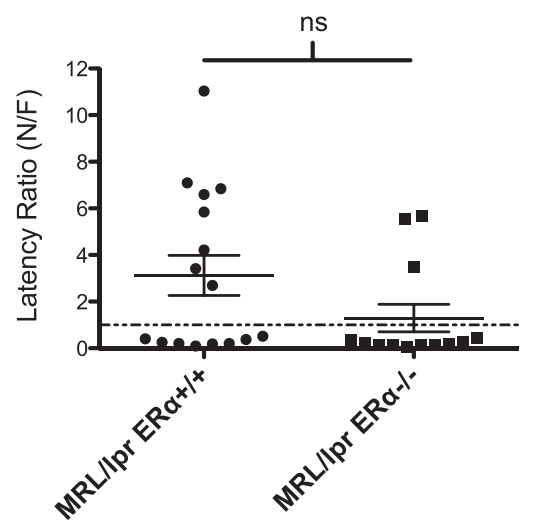

90min Retention Trial

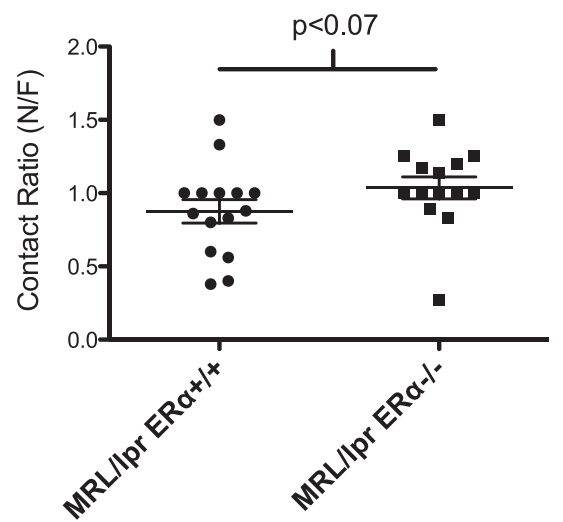

Figure $4 \mathrm{MRL} / \mathrm{Ipr}$ ERaKO mice perform better than MRL/Ipr WT in novel object recognition testing. (A) Relative discrimination (N-F/T) index. There was no significant difference between the discrimination ability of the MRL/lpr versus MRL/lpr ERaKO at 90 minutes or 24 hours. Neither group could effectively discriminate between the novel and familiar objects by this measure. A relative discrimination index of $0 \%$ (dotted line) indicates chance performance. (B) There was a significant difference in total exploration times between MRL/lpr and MRL/lpr ERaKO mice in both 90-minute and 24-hour trials. Post-hoc analysis revealed the total exploration time in both T1 and T2 of MRL/lpr ERaKO mice was higher than the total exploration time of MRL/lpr mice. (C) The latency ratio (time to first contact) was significantly decreased in the MRL/lpr ERaKO versus MRL/lpr mice at 90 minutes. There was also a trend towards improved performance in MRL/lpr ERaKO at 24 hours. (D) Contact ratio: MRL/Ipr ERaKO mice made significantly more nose contacts with the novel object than the familiar object at 24 hours, and at 90 minutes there was a trend towards significance. 


\section{NeuN - hippocampus}

\section{ER $\alpha \mathbf{W T}$}
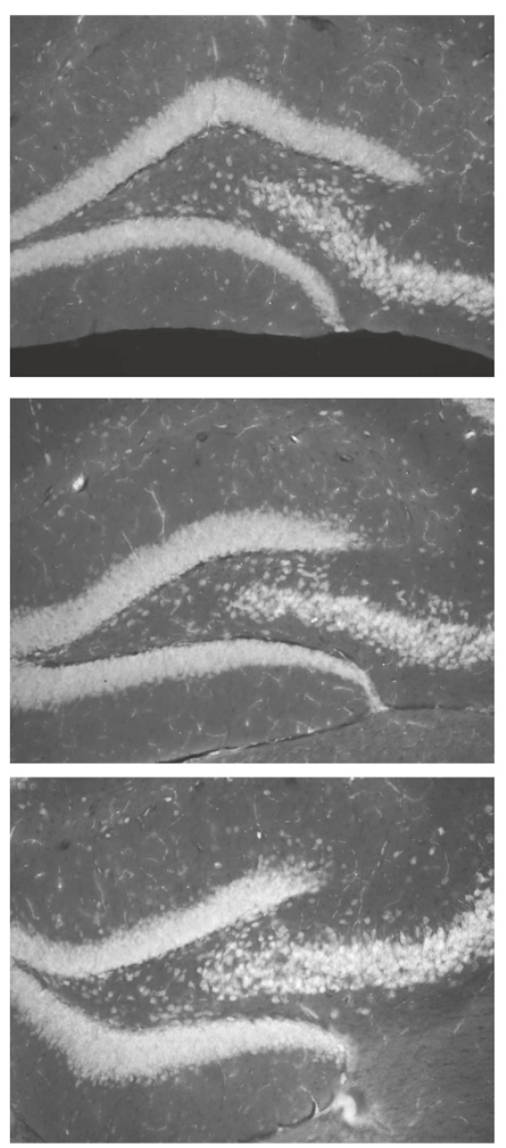

\section{$\mathrm{ER} \alpha \mathrm{KO}$}
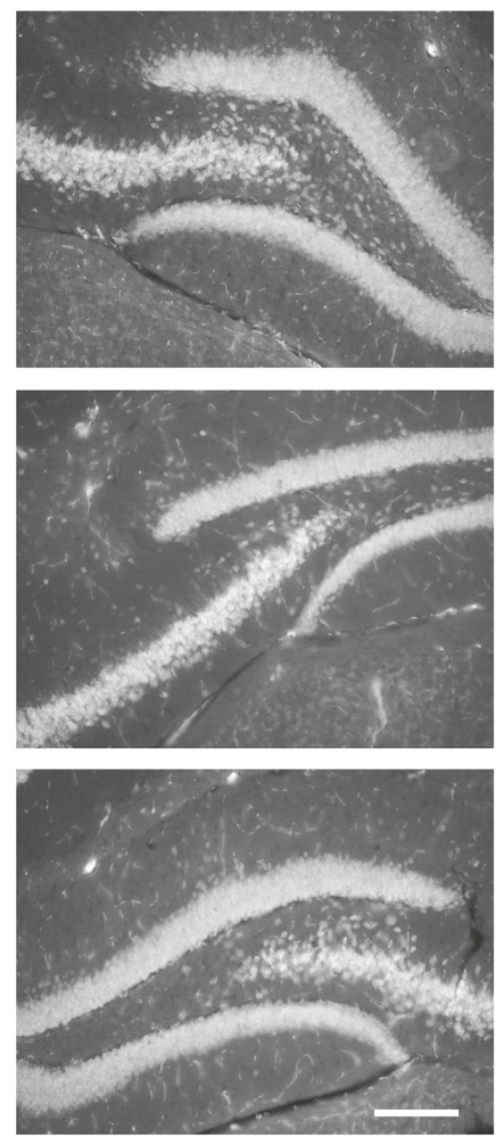

Figure 5 Hippocampal NeuN staining - MRL/Ipr and MRL/lpr ERaKO mice. Selected images of NeuN immunostaining in the hippocampus of $\mathrm{MRL} / \mathrm{lpr}$ and $\mathrm{MRL} / \mathrm{Ipr}$ ERaKO mice showing CA1 and dentate regions of interest ( $n=$ six to eight per group evaluated, three representative animals shown). There were no significant differences in hippocampal structure or volume noted. Scale bar in lower right corner represents 150 microns.

different between WT MRL/lpr and MRL/lpr ER $\alpha K O$ animals, based on the Iba1 immunohistochemistry. When semi-quantitative cell counts were undertaken in regards to Iba1 immunoreactivity, significant differences in both number and intensity of Iba1 staining within each microglial cell were observed. Hippocampal sections from MRL/lpr ER $\alpha K O$ had, on average, significantly fewer activated microglia compared with Iba1 immunoreactive microglia in the WT MRL/lpr group $(P=0.005-C A 1$, $P=0.015$ - dentate, Figure $6 \mathrm{C}$ ). The Iba1 data indicate that a potential mechanism for the cognitive protection in MRL/lpr ER $\alpha K O$ mice may be reduced inflammation or microgliosis.

\section{Discussion}

Of the one and a half million Americans afflicted with lupus, $90 \%$ are women, the vast majority of whom are between the ages of 15 and 45 years, when they are most hormonally active [51]. Approximately $60 \%$ of SLE patients have CNS or peripheral nervous system involvement, ranging from cognitive defects and mood disorders to severe presentations such as psychosis, seizure, stroke, and coma [52]. We hypothesized that ER $\alpha$ plays a role in NP-SLE by mediating local inflammation and/or modulating the $\mathrm{BBB}$, and that $\mathrm{ER} \alpha$ deficiency would protect against development of NP-SLE symptoms, based on the renal protection and survival benefit we previously reported in lupus ER $\alpha \mathrm{KO}$ mice. Our current data contribute to the previous literature by demonstrating that a mouse model of SLE (MRL/lpr mice) was protected from cognitive impairment when paired with an ER $\alpha K O$ mouse model, and our findings strongly suggest that cognitive improvement observed in the MRL/lpr ER $\alpha$ KO mice may be due to reduced activation of microglia in the hippocampus. Our laboratory previously showed that ER $\alpha$ is a key mediator of SLE in female lupus-prone mice (both 
A Iba1 - hippocampus

ER $\alpha$ WT
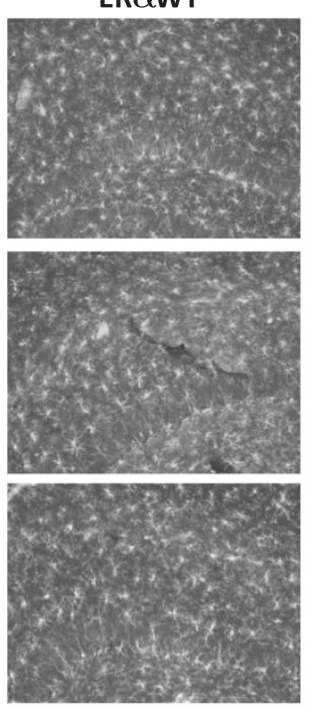

ERQKO
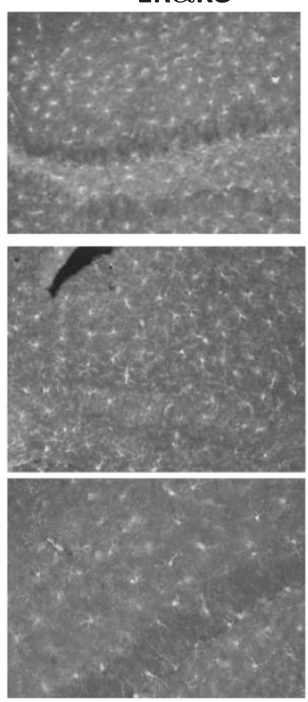

C

Iba1 in Hippocampus - CA1

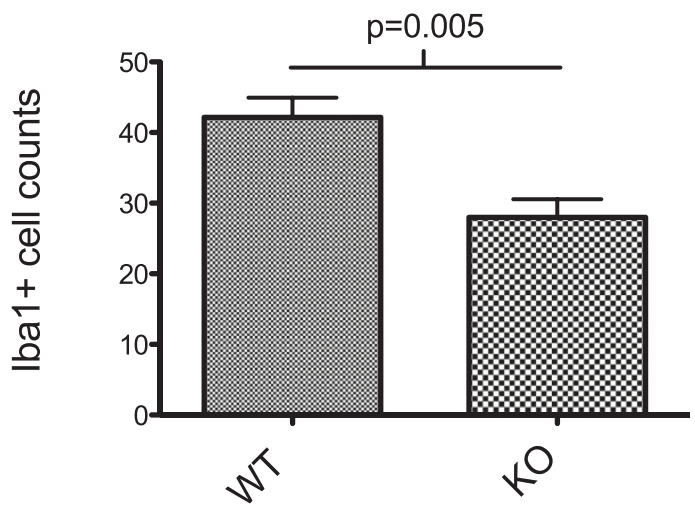

Iba1 in Hippocampus - Dentate

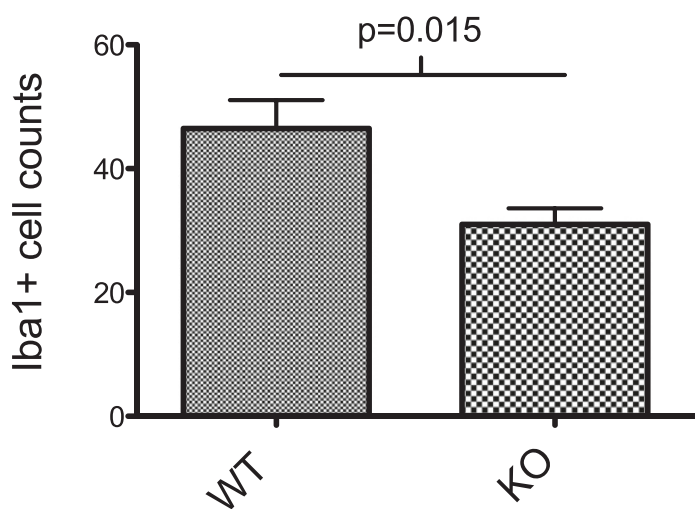

Figure 6 (See legend on next page.) 
NZM2410 and MRL/lpr) [21]. Deficiency of ER $\alpha$ in these mice resulted in significantly reduced renal disease and increased survival. This protective effect was independent of autoantibody production and immune complex deposition. These results indicate that ER $\alpha$ may be important in local modulation of the inflammatory response. In the present study, we investigated the effects of ER $\alpha$ deficiency in the brains of these mice. We analyzed cognitive endpoints in OVX lupus-prone mice, with estradiol replacement to control for the aberrantly high levels of estradiol and testosterone normally found in ER $\alpha \mathrm{KO}$ mice.

Similar to human lupus, MRL/lpr disease expression includes behavioral and neurologic dysfunction. The onset correlates with puberty and therefore raises the question of whether hormonal changes contribute to the disease process. Our findings herein are consistent with previous studies showing that MRL/lpr mice exhibit spatial memory deficits, as shown by weak performance in the Morris water maze and in linear maze acquisition [53,54]. In our current study, MRL/lpr mice were tested in a WRAM that does not rely on food reinforcement or food-seeking behavior (which could be confounded by differences in hormonal state or motivation). The WRAM also provides additional information over the Morris water maze regarding how the animals learn and recall as memory load increases, and therefore provides information regarding both working and reference spatial memory [55]. Consistent with previous maze studies in non-manipulated MRL/ lpr mice, our OVX E2-replete MRL/lpr mice performed poorly in memory testing, with abnormal learning curves in the WRAM regardless of the type of memory error.

The most obvious deficits were in late training periods (days 10 to 12) when MRL/lpr performed nearly as poorly as they did at days one to three and days four to six, suggesting that the vast majority of animals had not been able to 'learn the task'. The deficits observed in $\mathrm{MRL} / \mathrm{lpr}$ mice in this study were quite severe compared with the milder deficits seen in prior maze studies. One explanation is that the WRAM is a more rigorous test of spatial memory and may be more sensitive to detect impairment. Nonetheless, MRL/lpr ER $\alpha$ KO exhibited superior learning ability by all four measures of memory type, suggesting that lack of a functional ER $\alpha$ protects against full development of cognitive impairment in this disease model.

While there is a long line of evidence to support estradiol's role in improved memory and cognition, it is unlikely that ovariectomy alone explains the impaired performance in MRL/lpr, since estradiol levels were replete to physiologic levels. Importantly, estradiol levels did not correlate with behavior in either group, suggesting that estrogen alone could not rescue the phenotype. Thus, estradiol did not impact cognition via another (intact) receptor (such as ER $\beta$ ). It is possible that cyclical estrogen exposure (mimicking physiologic levels) might result in different outcomes (versus the continuous E2 dosing experienced by these animals), but this would not be expected in the absence of ER $\alpha$.

In addition to the WRAM, we utilized NOR testing to further study memory and cognition in these animals. NOR is attractive because it is a simple memory assay that relies mainly on the animal's innate exploratory behavior, without training or outside reinforcement [56], and relies on functional integrity both of the hippocampus and the frontal cortex [35]. The preference for the novel object relies on the supposition that the familiar object is remembered. Neither MRL/lpr nor MRL/lpr ER $\alpha K O$ mice could (as a group) reliably distinguish between objects at a short ( 90 minute) or long (24 hour) time point by relative discrimination index. This is in contrast to a previous study that revealed no significant deficit in NOR testing in MRL/lpr mice, although mice were tested with a shorter delay (45 minutes) in that study [47]. Our assessment was also more stringent in that rearing was not counted, and snout distance had to be $\leq 1 \mathrm{~cm}$ (versus $3 \mathrm{~cm}$ ).

There were, however, significant differences in total exploration time and object contacts between the groups, revealing a normalized propensity of MRL/lpr ER $\alpha$ KO mice to explore. Perhaps the best-studied neuropsychiatric abnormality in the MRL/lpr strain is the depressive-like behavior observed as early as five to six weeks of age. Using forced swim tests, multiple studies have shown 'behavioral despair' in these animals, as evidenced by voluntary immobility (floating), whereas normal animals swim vigorously to attempt escape $[47,48,57,58]$. Other symptoms of depressive behavior in these animals include anhedonia, apathy, and decreased activity. In rodents, the latter is often assessed as decreased exploration in a novel environment. In fact, MRL/lpr mice exhibit abnormal behavior in open field testing $[53,58-60]$. Thus, it is possible that the decreased exploration time, and lack of interest in the objects as a whole, is an indication of altered emotional reactivity, confounding the memory and cognitive aspect 
of the task. MRL/lpr ER $\alpha$ KO mice, in contrast, exhibited normal exploratory behavior in a novel environment. It is also possible that the significantly increased start arm errors committed by MRL/lpr mice in the WRAM were due to their tendency to return to the familiar, rather than explore the unknown. The behavioral performance in the earlier trials (trial one and two) within each day of the WRAM can also be used to detect motivation and/or mood disturbance. If mice perform poorly in early trials, this would suggest either inability or reduced motivation to swim and find the escape platform. Because the performance in the early trials of the WRAM did not appear to be different between the groups, this would suggest that motivation or mood were not affecting their ability to perform this task, while the NOR data instead suggest reduced exploratory behavior. Together, the WRAM and NOR testing suggest that MRL/lpr mice have both cognitive and emotional reactivity deficits, beginning at an early age, and that lack of a functional ER $\alpha$ is protective.

Studies in rodents and primates demonstrated that the hippocampus and perirhinal cortex are important for spatial and visual object recognition memory [61-64]. The CA1 zone of the hippocampus appears particularly vulnerable to behavior-related changes, and Sakic et al. found that CA1 pyramidal neuron dendrites atrophy in MRL/lpr mice [65]. This correlates with work done by DeGiorgio et al. that also showed specific degeneration of glutamatereceptor-positive neurons in the CA1 hippocampus after injection of the R4A autoantibody [8]. These previous findings motivated our decision to explore morphologic alterations in this particular brain region. In terms of global brain changes, MRL/lpr brain morphology studies documented enlarged ventricles and reduced parenchymal weights [65-67].

We examined the hippocampus and cortex from 20 $\mathrm{MRL} / \mathrm{lpr}$ and MRL/lpr ER $\alpha \mathrm{KO}$ mice and found that animals from both groups exhibited inflammatory changes in brain parenchyma as indicated by microgliosis, but that microgliosis was markedly attenuated in ER $\alpha K O$ brains. Western blot analysis did not reveal a significant difference in Ibal between the two groups, which may be secondary to the insensitivity of this assay to pick up focal changes and subtle differences in expression patterns within a particular cell type in that brain region, the sum of which may have a significant impact on disease state. Overall, the effects of ER $\alpha$ receptor activation are likely multifactorial, but these data suggest that there is indeed an ER $\alpha$-mediated inflammatory change in this model of chronic inflammation.

With regard to ER (and estrogen) beneficial or detrimental effects in the brain, the literature is extensive, but also full of inconsistencies, likely due to the pleiotropic nature of estrogen depending on disease state, cell type, dosing, timing, receptor-activating pathways, and so forth. Estradiol is highly lipophilic and can easily pass the BBB to modulate neuronal activity, particularly in the limbic system, which is rich in estrogen receptors. A role for estrogen receptors in neuroinflammation has been recognized. The selective estrogen receptor modulator (SERM) raloxifene, for example, can elicit robust neuroprotection against experimental autoimmune encephalomyelitis, partially via an inhibitory action on NF- $\mathrm{kB}$ and CCL20, a chemokine involved in neuroinflammation [68].

Our understanding of the pathophysiology of CNS lupus and the role of microglia in human disease is extremely limited. In a small series of seven patients with fatal neuropsychiatric lupus, widespread changes in the histologic features of the brain were present, including microinfarcts, microhemorrhages, thrombotic angiopathy, neuronal necrosis, reduced numbers of axons and neurons, and reactive microglia [69]. In vitro, microglia from primary cultures of human embryonic CNS cells, are the main producers of IL- 6 , IL- $1 \beta$, and tumor necrosis factor alpha (TNF $\alpha$ ) following stimulation with Tolllike receptor (TLR) 4 ligand or IL-1 $\beta$ [70]. In mice, brain atrophy, increased activation of microglia, and condensation of cytoplasm suggest a metabolic perturbation (for example, excitotoxic damage) that causes dysfunction and early death of central neurons during lupus-like disease [71]. Several investigators have demonstrated that $E R \alpha$ receptors are expressed by glial cells, and it has been shown that glial ER $\alpha$ expression increases with age [72]. This group also demonstrated that lowering ER $\alpha$ reversed aging-associated gliosis in the cortex, and partially restored E2-dependent neurite outgrowth, suggesting that ER $\alpha$ overexpression may be detrimental for neuroplasticity, and give rise to microglial activation. Although estrogen can inactivate microglia and inhibit the recruitment of $\mathrm{T}$ cells and macrophages into the CNS, there is controversy regarding which of the two estrogen receptors (ERs), ER $\alpha$ or ER $\beta$, mediates the beneficial effects in microglia. Our studies provided herein, suggest that the two estrogen receptors may have opposing effects on chronic neuroinflammation, since previous studies have indicated that ER $\beta$ agonists can suppress microglial activation in the brain [73], while our current findings indicate that a genetic knockout of the ER $\alpha$ receptor (leaving ER $\beta$ unopposed) has a similar effect, and therefore acts as a beneficial down-regulator of microglial response in our mice. Further studies will reveal whether ER $\alpha$ KO resulted in reduced activation of microglia via the classical and/or alternative activation pathways (which have diametrically opposed effects on brain physiology and behavior) [74]. Early development and migration of microglia to the CNS are also likely impacted by ER $\alpha$ deficiency since these cells originate from bone marrow myeloid progenitors that normally require ER $\alpha$ for expansion and differentiation $[75,76]$. 


\section{Conclusions}

Major efforts in the field are devoted to understanding estrogen influences on learning, memory, and mood, as well as the mechanisms that mediate these brain activities in both normal and disease states. The present study demonstrates that lack of ER $\alpha$ improves cognitive and emotional deficits of NP-SLE in female lupus-prone mice. The mechanism of this affect is not fully elucidated. The current study suggests that deletion of a functional ER $\alpha$ suppresses the pro-inflammatory actions of microglia and may contribute to reduction of sustained activation of microglia in this autoimmune disease. In humans, NP-SLE symptoms can be an early and devastating aspect of the disease. Further defining the effects of ER $\alpha$ in NP-SLE will provide new insight into mechanisms of disease and provide novel approaches to therapy.

\section{Additional files}

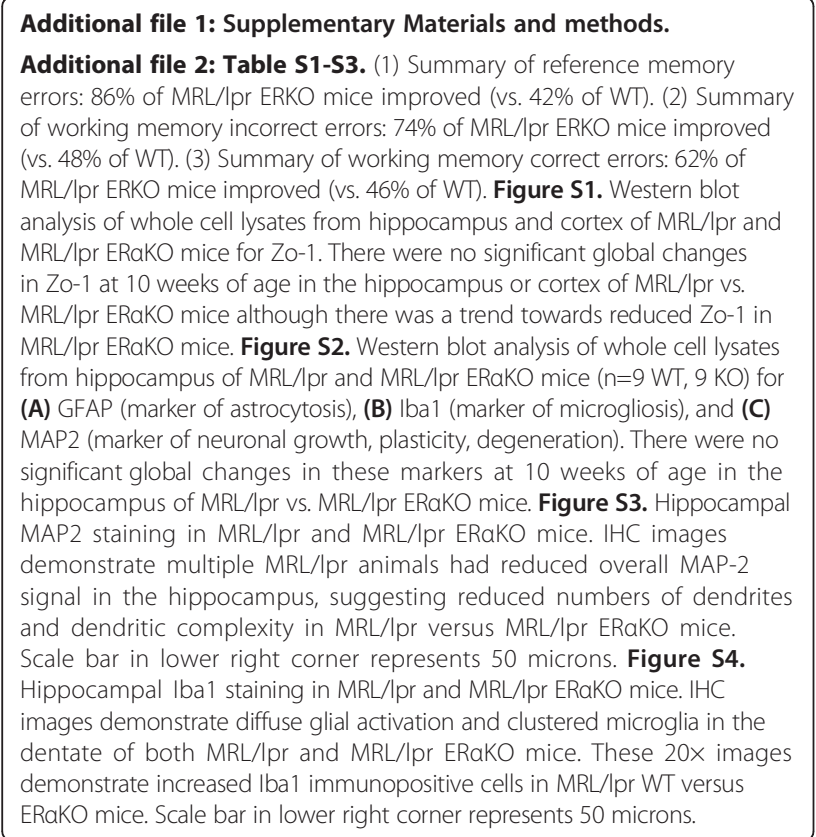

\begin{abstract}
Abbreviations
BBB: blood-brain barrier; CA1: Cornu Ammonis area 1; CCL20: chemokine ligand 20; CNS: central nervous system; CSF: cerebrospinal fluid; dsDNA: double stranded deoxyribonucleic acid; ERa: estrogen receptor alpha; ERR: estrogen receptor beta; GFAP: glial fibrillary acidic protein; Iba1: induction of brown adipose 1; IL1 $\beta$ : interleukin 1 beta; IL6: interleukin 6; MAP2: microtubule associated protein 2; MCP1: monocyte chemoattractant 1; MRL/lpr: Murphy Roths Large/lymphoproliferative; NFkB: nuclear factor kappa-light-chain-enhancer of activated B cells; NMDA receptors: N-Methyl-D-aspartate receptors; NOR: novel object recognition; NP-SLE: neuropsychiatric lupus; OVX: ovariectomy; SERM: selective estrogen receptor modulator; SLE: systemic lupus erythematosus; TLR: Toll-like receptor; TNFa: tumor necrosis factor alpha; WRAM: radial arm water maze.
\end{abstract}

\section{Competing interests}

The authors declare that they have no competing interests.

\section{Authors' contributions}

MC, ACG and GG directed the work, contributed to designing the study, and reviewed/interpreted the data. $M C$ and JW conducted all behavior studies and Western blotting. MC, JW, LF, HB, and ACG all contributed to performing and analyzing $\mathrm{IHC}$ experiments. MC prepared the manuscript, figures, and tables. GG and ACG contributed to manuscript revisions. All authors read and approved the final manuscript.

\section{Acknowledgements}

The authors wish to thank Ms Claudia Umphlet and Dr Michael Smith for help with tissue processing. This publication was supported by the Office of Research on Women's Health: Specialized Centers of Research on Sex and Gender Factors Affecting Women's Health (NIH/NIAMS - National Institutes of Health/National Institute of Arthritis and Musculoskeletal and Skin diseases, grant number: P50 DA016511); The South Carolina Clinical \& Translational Research Institute, with an academic home at the Medical University of South Carolina (NIH/NCRR - National Instititutes of Health/ National Center for Research Resources, grant numbers: UL1 RR029880 and UL1 RR029882); and a VA Medical Research Service merit award (grant number: 1101BX000470-01). The contents are solely the responsibility of the authors and do not necessarily represent the official views of the NIH or NCRR.

Received: 14 July 2014 Accepted: 25 September 2014

Published online: 16 December 2014

\section{References}

1. Lahita RG: The role of sex hormones in systemic lupus erythematosus. Curr Opin Rheumatol 1999, 11:352-356.

2. The American College of Rheumatology nomenclature and case definitions for neuropsychiatric lupus syndromes. Arthritis Rheum 1999, 42:599-608.

3. Brey RL, Holliday SL, Saklad AR, Navarrete MG, Hermosillo-Romo D, Stallworth CL, Valdez CR, Escalante A, del Rincon I, Gronseth G, Rhine CB, Padilla P, McGlasson D: Neuropsychiatric syndromes in lupus: prevalence using standardized definitions. Neurology 2002, 58:1214-1220.

4. Ainiala H, Loukkola J, Peltola J, Korpela M, Hietaharju A: The prevalence of neuropsychiatric syndromes in systemic lupus erythematosus. Neurology 2001, 57:496-500.

5. Sabbadini MG, Manfredi AA, Bozzolo E, Ferrario L, Rugarli C, Scorza R, Origgi L, Vanoli M, Gambini O, Vanzulli L, Croce D, Campana A, Messa C, Fazio F, Tincani A, Anzola G, Cattaneo R, Padovani A, Gasparotti R, Gerli R, Quartesan R, Piccirilli M, Farsi A, Emmi E, Passaleva A, Domeneghetti M, Piccini C, Massacesi L, Pupi A, De Cristoforis M, Danieli M, Candela P, Fraticelli M, Bartolini U, Salvolini G, Danieli G, Passaleva A: Central nervous system involvement in systemic lupus erythematosus patients without overt neuropsychiatric manifestations. Lupus 1999, 8:11-19.

6. Carbotte RM, Denburg SD, Denburg JA: Cognitive dysfunction in systemic lupus erythematosus is independent of active disease. J Rheumatol 1995, 22:863-867.

7. van Dam AP: Diagnosis and pathogenesis of CNS lupus. Rheumatol Int 1991, 11:1-11.

8. DeGiorgio LA, Konstantinov KN, Lee SC, Hardin JA, Volpe BT, Diamond B: A subset of lupus anti-DNA antibodies cross-reacts with the NR2 glutamate receptor in systemic lupus erythematosus. Nat Med 2001, 7:1189-1193.

9. Faust TW, Chang EH, Kowal C, Berlin R, Gazaryan IG, Bertini E, Zhang J, Sanchez-Guerrero J, Fragoso-Loyo HE, Volpe BT, Diamond B, Huerta PT: Neurotoxic lupus autoantibodies alter brain function through two distinct mechanisms. Proc Natl Acad Sci U S A 2010, 107:18569-18574.

10. Kowal C, Degiorgio LA, Lee JY, Edgar MA, Huerta PT, Volpe BT, Diamond B: Human lupus autoantibodies against NMDA receptors mediate cognitive impairment. Proc Natl Acad Sci U S A 2006, 103:19854-19859.

11. Fragoso-Loyo H, Cabiedes J, Orozco-Narvaez A, Davila-Maldonado L, Atisha-Fregoso Y, Diamond B, Llorente L, Sanchez-Guerrero J: Serum and cerebrospinal fluid autoantibodies in patients with neuropsychiatric lupus erythematosus: implications for diagnosis and pathogenesis. PLoS One 2008, 3:e3347.

12. Husebye ES, Sthoeger ZM, Dayan M, Zinger H, Elbirt D, Levite M, Mozes E: Autoantibodies to a NR2A peptide of the glutamate/NMDA receptor in sera of patients with systemic lupus erythematosus. Ann Rheum Dis 2005, 64:1210-1213. 
13. Arinuma $Y$, Yanagida $T$, Hirohata $S$ : Association of cerebrospinal fluid anti-NR2 glutamate receptor antibodies with diffuse neuropsychiatric systemic lupus erythematosus. Arthritis Rheum 2008, 58:1130-1135.

14. Diamond B, Huerta PT, Mina-Osorio P, Kowal C, Volpe BT: Losing your nerves? Maybe it's the antibodies. Nat Rev Immunol 2009, 9:449-456.

15. Kowal C, DeGiorgio LA, Nakaoka T, Hetherington H, Huerta PT, Diamond B, Volpe BT: Cognition and immunity; antibody impairs memory. Immunity 2004, 21:179-188.

16. Paterni I, Granchi C, Katzenellenbogen JA, Minutolo F: Estrogen receptors alpha (ERalpha) and beta (ERbeta): Subtype-selective ligands and clinical potential. Steroids 2014, 90C:13-29.

17. Roof RL, Hall ED: Estrogen-related gender difference in survival rate and cortical blood flow after impact-acceleration head injury in rats. J Neurotrauma 2000, 17:1155-1169.

18. Roof RL, Hall ED: Gender differences in acute CNS trauma and stroke: neuroprotective effects of estrogen and progesterone. J Neurotrauma 2000, 17:367-388

19. Polanczyk M, Zamora A, Subramanian S, Matejuk A, Hess DL, Blankenhorn EP, Teuscher C, Vandenbark AA, Offner $\mathrm{H}$ : The protective effect of 17beta-estradiol on experimental autoimmune encephalomyelitis is mediated through estrogen receptor-alpha. Am J Pathol 2003, 163:1599-1605.

20. Morales LB, Loo KK, Liu HB, Peterson C, Tiwari-Woodruff S, Voskuhl RR: Treatment with an estrogen receptor alpha ligand is neuroprotective in experimental autoimmune encephalomyelitis. J Neurosci 2006, 26:6823-6833

21. Svenson JL, EuDaly J, Ruiz P, Korach KS, Gilkeson GS: Impact of estrogen receptor deficiency on disease expression in the NZM2410 lupus prone mouse. Clin Immunol 2008, 128:259-268.

22. Grimaldi CM, Jeganathan V, Diamond B: Hormonal regulation of B cell development: 17 beta-estradiol impairs negative selection of high-affinity DNA-reactive $B$ cells at more than one developmental checkpoint. J Immunol 2006, 176:2703-2710.

23. Grimaldi CM, Michael DJ, Diamond B: Cutting edge: expansion and activation of a population of autoreactive marginal zone $B$ cells in a model of estrogen-induced lupus. J Immunol 2001, 167:1886-1890.

24. Sawalha AH, Kovats S: Dehydroepiandrosterone in systemic lupus erythematosus. Curr Rheumatol Rep 2008, 10:286-291.

25. Cook LC, Hillhouse AE, Myles MH, Lubahn DB, Bryda EC, Davis JW, Franklin $\mathrm{CL}$ : The role of estrogen signaling in a mouse model of inflammatory bowel disease: a Helicobacter hepaticus model. PLoS One 2014, 9:e94209.

26. Cunningham MA, Naga OS, Eudaly JG, Scott JL, Gilkeson GS: Estrogen receptor alpha modulates Toll-like receptor signaling in murine lupus. Clin Immunol 2012, 144:1-12.

27. Wen YR, Tan PH, Cheng JK, Liu YC, Ji RR: Microglia: a promising target for treating neuropathic and postoperative pain, and morphine tolerance. J Formos Med Assoc 2011, 110:487-494.

28. Sierra A, Gottfried-Blackmore A, Milner TA, McEwen BS, Bulloch K: Steroid hormone receptor expression and function in microglia. Glia 2008, 56:659-674.

29. Smith JA, Das A, Butler JT, Ray SK, Banik NL: Estrogen or estrogen receptor agonist inhibits lipopolysaccharide induced microglial activation and death. Neurochem Res 2011, 36:1587-1593.

30. Crusio WE, Schwegler H: Learning spatial orientation tasks in the radial-maze and structural variation in the hippocampus in inbred mice. Behav Brain Funct 2005, 1:3

31. Lockrow J, Boger H, Bimonte-Nelson H, Granholm AC: Effects of long-term memantine on memory and neuropathology in Ts65Dn mice, a model for Down syndrome. Behav Brain Res 2011, 221:610-622.

32. Bimonte HA, Denenberg VH: Estradiol facilitates performance as working memory load increases. Psychoneuroendocrinology 1999, 24:161-173.

33. Hyde LA, Hoplight BJ, Denenberg VH: Water version of the radial-arm maze: learning in three inbred strains of mice. Brain Res 1998, 785:236-244.

34. Alamed J, Wilcock DM, Diamond DM, Gordon MN, Morgan D: Two-day radial-arm water maze learning and memory task; robust resolution of amyloid-related memory deficits in transgenic mice. Nat Protoc 2006, 1:1671-1679.

35. Rainer $G$, Ranganath $C$ : Coding of objects in the prefrontal cortex in monkeys and humans. Neuroscientist 2002, 8:6-11.

36. Gilkeson GS, Grudier JP, Karounos DG, Pisetsky DS: Induction of anti-double stranded DNA antibodies in normal mice by immunization with bacterial DNA. J Immunol 1989, 142:1482-1486.
37. Levin-Allerhand JA, Sokol K, Smith JD: Safe and effective method for chronic 17beta-estradiol administration to mice. Contemp Top Lab Anim Sci 2003, 42:33-35.

38. Haisenleder DJ, Schoenfelder AH, Marcinko ES, Geddis LM, Marshall JC Estimation of estradiol in mouse serum samples: evaluation of commercial estradiol immunoassays. Endocrinology 2011, 152:4443-4447.

39. Lockrow J, Boger H, Gerhardt G, Aston-Jones G, Bachman D, Granholm AC: A noradrenergic lesion exacerbates neurodegeneration in a Down syndrome mouse model. J Alzheimers Dis 2011, 23:471-489.

40. Freeman LR, Granholm AC: Vascular changes in rat hippocampus following a high saturated fat and cholesterol diet. J Cereb Blood Flow Metab 2012, 32:643-653.

41. Granholm AC, Ford KA, Hyde LA, Bimonte HA, Hunter CL, Nelson M, Albeck D, Sanders LA, Mufson EJ, Crnic LS: Estrogen restores cognition and cholinergic phenotype in an animal model of Down syndrome. Physiol Behav 2002, 77:371-385.

42. Bimonte HA, Nelson ME, Granholm AC: Age-related deficits as working memory load increases: relationships with growth factors. Neurobiol Aging 2003, 24:37-48.

43. Bimonte $H A$, Denenberg VH: Sex differences in vicarious trial-anderror behavior during radial arm maze learning. Physiol Behav 2000, 68:495-499.

44. Antunes M, Biala G: The novel object recognition memory: neurobiology, test procedure, and its modifications. Cogn Process 2012, 13:93-110.

45. Mumby DG, Wood ER, Duva CA, Kornecook TJ, Pinel JP, Phillips AG: Ischemia-induced object-recognition deficits in rats are attenuated by hippocampal ablation before or soon after ischemia. Behav Neurosci 1996, 110:266-281.

46. Reed JM, Squire LR: Impaired recognition memory in patients with lesions limited to the hippocampal formation. Behav Neurosci 1997, 111:667-675.

47. Gao HX, Campbell SR, Cui MH, Zong P, Hee-Hwang J, Gulinello M, Putterman C: Depression is an early disease manifestation in lupus-prone MRL/lpr mice. J Neuroimmunol 2009, 207:45-56.

48. Gao HX, Sanders E, Tieng AT, Putterman C: Sex and autoantibody titers determine the development of neuropsychiatric manifestations in lupus-prone mice. J Neuroimmunol 2010, 229:112-122.

49. Asl SZ, Khaksari M, Khachki AS, Shahrokhi N, Nourizade S: Contribution of estrogen receptors alpha and beta in the brain response to traumatic brain injury. J Neurosurg 2013, 119:353-361.

50. Shin JA, Yang SJ, Jeong SI, Park HJ, Choi YH, Park EM: Activation of estrogen receptor beta reduces blood-brain barrier breakdown following ischemic injury. Neuroscience 2013, 235:165-173.

51. Demas KL, Costenbader $\mathrm{KH}$ : Disparities in lupus care and outcomes. Curr Opin Rheumatol 2009, 21:102-109.

52. Unterman A, Nolte JE, Boaz M, Abady M, Shoenfeld Y, Zandman-Goddard G: Neuropsychiatric syndromes in systemic lupus erythematosus: a meta-analysis. Semin Arthritis Rheum 2011, 41:1-11.

53. Sakic B, Szechtman $H$, Keffer M, Talangbayan $H$, Stead R, Denburg JA A behavioral profile of autoimmune lupus-prone MRL mice. Brain Behav Immun 1992, 6:265-285.

54. Vogelweid CM, Wright DC, Johnson JC, Hewett JE, Walker SE: Evaluation of memory, learning ability, and clinical neurologic function in pathogen-free mice with systemic lupus erythematosus. Arthritis Rheum 1994, 37:889-897.

55. Bimonte HA, Hyde LA, Hoplight BJ, Denenberg VH: In two species, females exhibit superior working memory and inferior reference memory on the water radial-arm maze. Physiol Behav 2000, 70:311-317.

56. Dere E, Huston JP, De Souza Silva MA: The pharmacology, neuroanatomy and neurogenetics of one-trial object recognition in rodents. Neurosci Biobehav Rev 2007, 31:673-704

57. Sakic B, Lacosta S, Denburg JA, Szechtman H: Altered neurotransmission in brains of autoimmune mice: pharmacological and neurochemical evidence. J Neuroimmunol 2002, 129:84-96.

58. Sakic B, Szechtman H, Talangbayan H, Denburg SD, Carbotte RM, Denburg JA: Disturbed emotionality in autoimmune MRL-Ipr mice. Physiol Behav 1994, 56:609-617.

59. Choleris E, Thomas AW, Kavaliers M, Prato FS: A detailed ethological analysis of the mouse open field test: effects of diazepam, chlordiazepoxide and an extremely low frequency pulsed magnetic field. Neurosci Biobehav Rev 2001, 25:235-260. 
60. Szechtman H, Sakic B, Denburg JA: Behaviour of MRL mice: an animal model of disturbed behaviour in systemic autoimmune disease. Lupus 1997, 6:223-229.

61. Hammond RS, Tull LE, Stackman RW: On the delay-dependent involvement of the hippocampus in object recognition memory. Neurobiol Learn Mem 2004, 82:26-34.

62. Aggleton JP, O'Mara SM, Vann SD, Wright NF, Tsanov M, Erichsen JT: Hippocampal-anterior thalamic pathways for memory: uncovering a network of direct and indirect actions. Eur J Neurosci 2010, 31:2292-2307.

63. Buckmaster CA, Eichenbaum H, Amaral DG, Suzuki WA, Rapp PR: Entorhinal cortex lesions disrupt the relational organization of memory in monkeys. J Neurosci 2004, 24:9811-9825.

64. Clark RE, Zola SM, Squire LR: Impaired recognition memory in rats after damage to the hippocampus. J Neurosci 2000, 20:8853-8860.

65. Sakic B, Szechtman H, Denburg JA, Gorny G, Kolb B, Whishaw IQ: Progressive atrophy of pyramidal neuron dendrites in autoimmune MRL-Ipr mice. J Neuroimmunol 1998, 87:162-170.

66. Farrell M, Sakic B, Szechtman H, Denburg JA: Effect of cyclophosphamide on leukocytic infiltration in the brain of MRL/lpr mice. Lupus 1997, 6:268-274.

67. Denenberg VH, Sherman GF, Rosen GD, Morrison L, Behan PO, Galaburda AM: A behavior profile of the MRL/Mp Ipr/lpr mouse and its association with hydrocephalus. Brain Behav Immun 1992, 6:40-49.

68. Li R, Xu W, Chen Y, Qiu W, Shu Y, Wu A, Dai Y, Bao J, Lu Z, Hu X: Raloxifene suppresses experimental autoimmune encephalomyelitis and NF-kappaB-dependent CCL20 expression in reactive astrocytes. PLoS One 2014, 9:e94320.

69. Brooks WM, Sibbitt WL Jr, Kornfeld M, Jung RE, Bankhurst AD, Roldan CA: The histopathologic associates of neurometabolite abnormalities in fatal neuropsychiatric systemic lupus erythematosus. Arthritis Rheum 2010, 62:2055-2063.

70. Sebire G, Emilie D, Wallon C, Hery C, Devergne O, Delfraissy JF, Galanaud P, Tardieu M: In vitro production of IL-6, IL-1 beta, and tumor necrosis factor-alpha by human embryonic microglial and neural cells. J Immunol 1993, 150:1517-1523.

71. Ballok DA, Ma X, Denburg JA, Arsenault L, Sakic B: Ibuprofen fails to prevent brain pathology in a model of neuropsychiatric lupus. J Rheumato/ 2006, 33:2199-2213.

72. Arimoto JM, Wong A, Rozovsky I, Lin SW, Morgan TE, Finch CE: Age increase of estrogen receptor-alpha (ERalpha) in cortical astrocytes impairs neurotrophic support in male and female rats. Endocrinology 2013, 154:2101-2113.

73. Wu WF, Tan XJ, Dai YB, Krishnan V, Warner M, Gustafsson JA: Targeting estrogen receptor beta in microglia and T cells to treat experimental autoimmune encephalomyelitis. Proc Natl Acad Sci U S A 2013, 110:3543-3548.

74. Giunti D, Parodi B, Cordano C, Uccelli A, Kerlero de Rosbo N: Can we switch microglia's phenotype to foster neuroprotection? Focus on multiple sclerosis. Immunology 2014, 141:328-339.

75. Carreras E, Turner S, Frank MB, Knowlton N, Osban J, Centola M, Park CG, Simmons A, Alberola-lla J, Kovats S: Estrogen receptor signaling promotes dendritic cell differentiation by increasing expression of the transcription factor IRF4. Blood 2010, 115:238-246.

76. Douin-Echinard V, Laffont S, Seillet C, Delpy L, Krust A, Chambon P, Gourdy P, Arnal JF, Guery JC: Estrogen receptor alpha, but not beta, is required for optimal dendritic cell differentiation and [corrected] CD40-induced cytokine production. J Immunol 2008, 180:3661-3669.

doi:10.1186/s12974-014-0171-x

Cite this article as: Cunningham et al:: Estrogen receptor alpha deficiency protects against development of cognitive impairment in murine lupus. Journal of Neuroinflammation 2014 11:171.

\section{Submit your next manuscript to BioMed Central and take full advantage of:}

- Convenient online submission

- Thorough peer review

- No space constraints or color figure charges

- Immediate publication on acceptance

- Inclusion in PubMed, CAS, Scopus and Google Scholar

- Research which is freely available for redistribution

Submit your manuscript at www.biomedcentral.com/submit 